\title{
Botryoid sarcoma of the prostatic stroma: a case report
}

\begin{abstract}
Rhabdomyosarcoma (RMS) constitutes 3\% of malignant tumors in the pediatric age and $2 \%$ in the adolescents. The most frequent subtypes are embryonic $(50 \%)$ and alveolar $(40 \%)$. Within the RMS the embryonic subtype the botryoid variety is the least common and only corresponds to $8 \%$ of all. We presented a radiological clinical case of a three-year-old boy with hematuria. Imaging studies were performed, evidencing a tumor lesion in the prostate projection. Surgery and pathology studies confirmed RMS botryoid variety. The infrequency and importance of early diagnosis in childhood motivated the authors to present the case. Key words: rhabdomyosarcoma, rhabdomyosarcoma botryoid variety, hematuria, prostate.
\end{abstract}

Volume 2 Issue 6 - 2018

\author{
Yanae González Aquino,' Jorge Ortiz \\ Roque, ${ }^{2}$ Rayner Menéndez Pérez, ${ }^{3}$ Juan \\ Felipe Mantilla Hernández ${ }^{4}$ \\ 'Master en urgencias médicas, especialista en MGl y Radiología. \\ Profesora instructora. Hospital Pediátrico de Centro Habana, La \\ Habana-Cuba \\ ${ }^{2}$ Master en urgencias médicas, especialista en MGI y Radiología. \\ Profesor Auxiliar, investigador agregado, Hospital Clínico \\ Quirúrgico Hermanos Ameijeiras, La Habana-Cuba \\ ${ }^{3}$ Especialista en Medicina Interna, médico nuclear. Profesor \\ instructor, Hospital Clínico Quirúrgico Hermanos Ameijeiras, La \\ Habana-Cuba \\ ${ }^{4}$ Residente de II año de radiología, Hospital Clínico Quirúrgico \\ Hermanos Ameijeiras, La Habana-Cuba
}
Correspondence: Jorge Ortiz Roque, Master en urgencias médicas, especialista en MGl y Radiología. Profesor Auxiliar, investigador agregado. Hospital Clínico Quirúrgico Hermanos Ameijeiras, La Habana Cuba, Tel +5358320554 ,
Email jorge.ortez@infomed.sld.cu

Received: May II, 2018 | Published: December 13, 2018

\section{Introduction}

The RMS were first described by Wiegner in 1850, then Monckegerg in 1907 described the first bladder RMS and later Houette in 1929 reported it in a bladder congenital diverticulum, however in 1972 it was created the Study Group of Rhabdomyosarcoma Intergrupos (IRSG for its acronym in English) to investigate the biology and therapeutic advances in this type of tumors. ${ }^{1}$ RMS is a malignant tumor of primitive mesenchymal origin that possesses the biological and phenotypic characteristics of skeletal muscle in development (rhabdomyoblasts). ${ }^{1}$ It is the third most common extracranial tumor in childhood and its location in the lower urinary tract is one of the most common ( $24 \%$ ), but very few cases have been described in the prostatic stroma. ${ }^{2}$ It has four varieties: botryoid, alveolar, undifferentiated and pleomorphic. The embryonal polypoid RMS (botryoid) is the one that has the best prognosis if it is detected early before it does local or distant extension, ${ }^{3}$ however the bladder or prostate localization places it as an unfavorable prognosis according to the risk groups. ${ }^{4}$ Associations have been described in $32 \%$, with a variety of syndromes including: Castello syndrome, Li-Fraumeni syndrome, Beckwith-Wiedemann syndrome, neurofibromatosis type 1, among others. Early diagnosis will enable timely treatment and the greatest possibility of a complete response to treatment. Radiology as a complement to the clinical epidemiological method plays a fundamental role, both for diagnosis and for monitoring, where radiological protection is a crucial element in childhood.

Hematuria and disorders for urination are frequent signs and symptoms in childhood that must be studied in detail. X-rays of the abdomen and pelvis are usually useful to rule out stones or bone defects, however the safety of renal and bladder ultrasound, place it as the study of choice, which can be complemented with color and power Doppler. Urethrocystography in young children is useful to assess bladder capacity, anatomy of the area and its relationship with the rest of the structures. Simple computed tomography with intravenous contrast would also show lesion densities, vascular relationships and compromise, as well as help with local and distant extension. Magnetic resonance imaging is a useful tool to assess injury and local extension. The importance of timely and adequate detection of childhood injuries, with the optimization of the studies, motivated the authors to present a radiological clinical case of a child, with a pelvic mass and urinary disorders, which infrequently leads to socialization in the scientific community for differential diagnoses, in addition to sensitizing family members or those responsible for children, where the interrogation does not provide sufficient data, and insight and observation.

\section{Clinical case}

A three-year-old child, a third-pregnancy product with no relevant history, is admitted to the urology service of the pediatric hospital of Centro Habana due to haematuria and intermittent difficulty in urination, which lasted 3 months. The physical and complementary blood tests were not relevant, so the pediatrician referred him to the radiology department to perform abdominal ultrasound which reported the presence in the pelvic excavation a solid well-defined echogenic mass measuring $7.1 \times 6.0 \times 5.5 \mathrm{~cm}$ in intimate relationship with the prostate and indistinguishable from said structure, which elevates the bladder floor, with areas that cannot be defined if they are intravesical. Color Doppler shows vascularization in both the interior and the periphery of the lesion, associated with slight bilateral ureterohydronephrosis predominantly left, without demonstrating other positive findings by such examination. Figure 1 Subsequently, retrograde and voiding urethrocystography was performed, which showed a mass with growth inside the bladder in frontal and oblique projection, which impresses independently of its wall, which causes a defect in the floor of the bladder with a polylobulated appearance. Measures described. Figure 2 and 3 A presumptive diagnosis of 
bladder tumor is established, with differential diagnoses as early childhood extravesical tumors such as rhabdomyosarcoma and benign tumors of the lower urinary tract (leiomyoma, fibroma, neurofibroma, hemangioma), the latter extremely rare, as well as bladder polyps. A cystoscopy was performed to establish a diagnosis (for suspicion of bladder injury), to evaluate characteristics of the lesion and to obtain a sample for biopsy.

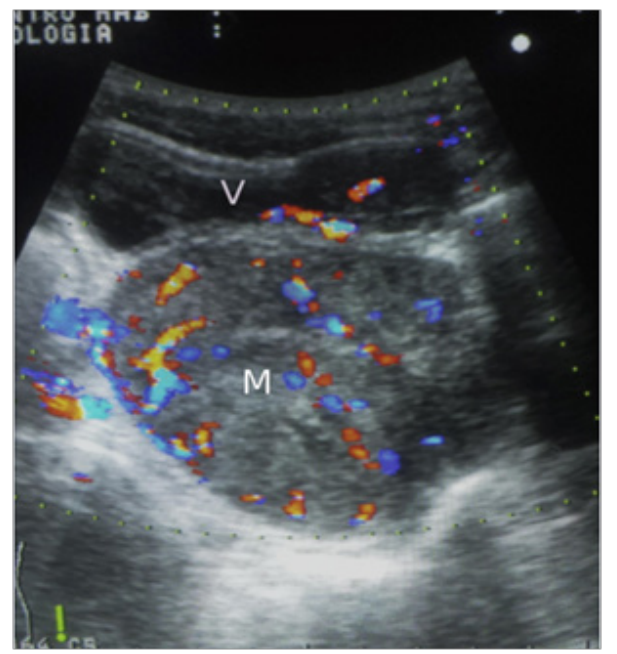

Figure I Ultrasound in B-mode and color Doppler, cross-section at the level of the hypogastrium showing an echogenic mass (M) with well-defined edges, not encapsulated, without invasion of neighboring tissues, which previously displaces the bladder (V).
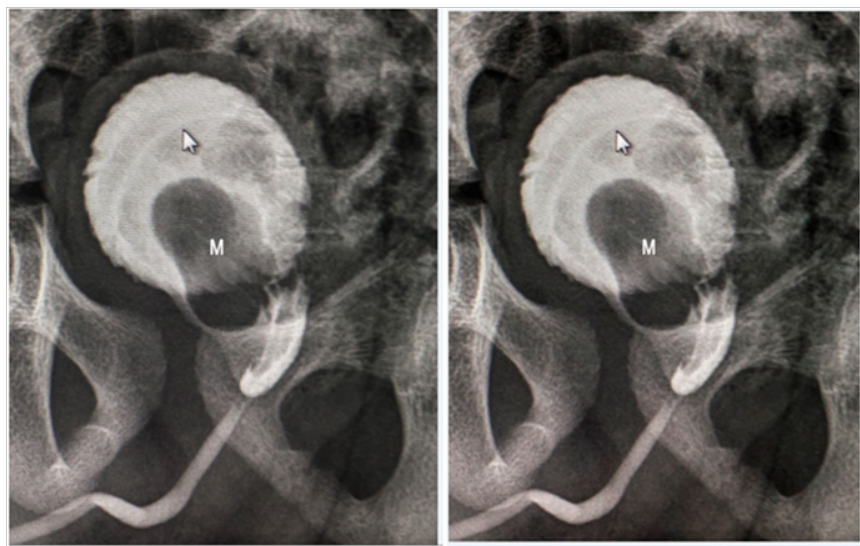

Figure 2 Mictric urethrocystography in left anterior oblique projection showing a full defect $(M)$ that seems to originate from the anterior region of the prostatic urethra, without obstructing its light, which grows lobularly inside the bladder (solid white arrow).

In addition, extension studies were performed: chest $\mathrm{x}$-ray (not shown) and computed tomography of the thorax and abdomen, which corroborated the presence of slight bilateral hydronephrosis due to expansive process, with well-defined contours, which grew from the prostate to the posterior urethra and bladder, compressing it, without ruling out the possibility of infiltration of it. Figure 3 after contrast administration, the lesion showed enhancement, corroborating its possible prostatic origin. There was no evidence of secondary appearance lesions at other levels, or locoregional adenopathies, with the studies performed. Figure 4 the histology of the tumor showed the existence of a botryoid variety rhabdomyosarcoma from the prostatic stroma. The lesion was resected without immediate complications and to date there is no evidence of tumor recurrence or the appearance of new symptoms.

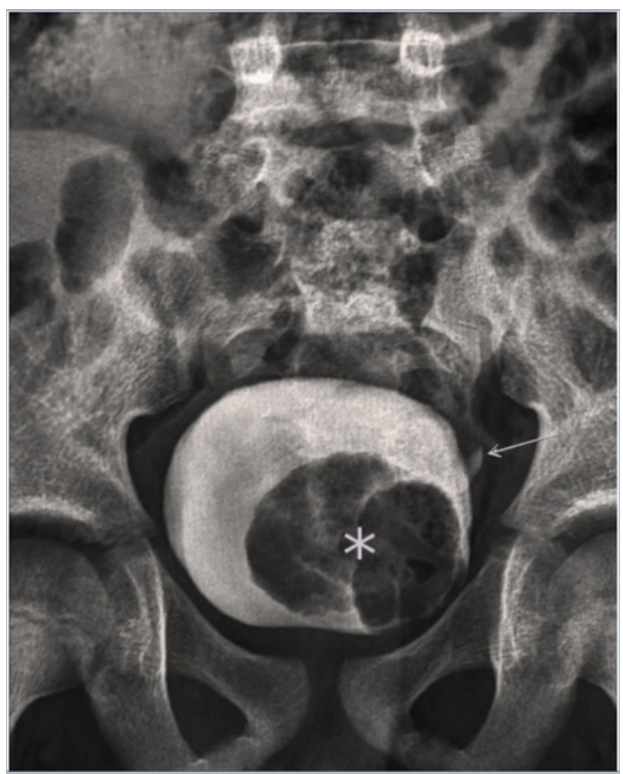

Figure 3 Cystography in frontal projection showing a polylobulated fullness defect in the bladder floor $\left(^{*}\right)$ as well as slight left vesicoureteral reflux (arrow).

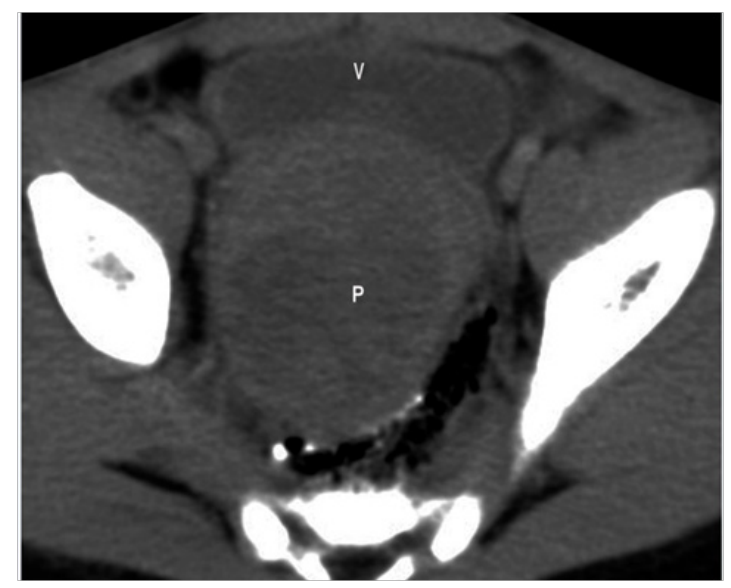

Figure 4 Computerized axial tomography with intravenous and oral contrast, Axial section at the hypogastric level, where the prostate $(P)$ is visualized; the expansive process with post contrast enhancement and bladder (V), as well as neighboring structures (soft and bony parts).

Discussion RMS only accounts for 3\% of malignant neoplasms in childhood and $2 \%$ in adolescence and although the genitourinary origin is the most frequent, very few publications have reported their origin in the prostatic stroma. ${ }^{5,6}$ They have a distribution that by their frequency are: head and neck, $35 \%$; genitourinary tract, $26 \%$; extremities, $19 \%$; and others, $20 \% .^{7}$ The main organs in which distant metastasis occurs are the lung, bone marrow, lymph nodes and bone. The radiological characteristics of this type of tumor can hinder the differentiation of other intravesical neoplasms, by the growth inside the bladder, the base of implantation, the infiltration and / or extension to neighboring structures (urethra, vagina, perirectal tissue) as well as Ultrasonic characteristics such as solid consistency, sometimes indistinguishable from adjacent tissues, as well as the flow that is collected inside it. Prostate rhabdomyosarcoma is more common 
than bladder and its early haematological dissemination is to the bone marrow and lung. The treatment is based on the clinical stage, the location of the primary tumor and the extent of the disease. Many cases surgical treatment is based on bladder preservation and prostatectomy with reconstruction of the urethra or bladder neck, chemotherapy and radiotherapy. ${ }^{7}$ Therefore, the relevance and relevance of presenting this case with teaching and research objectives, which contribute to raising the scientific-epidemiological thinking in undergraduate and graduate students and in medical personnel in general. Benign tumors are much less frequent, so the differential diagnosis should not delay histological confirmation and extension studies in these patients.

\section{Conclusion}

Rabomyosarcoma botryoid variety of prostatic stroma.

\section{Acknowledgments}

None.

\section{Conflicts of interest}

The author declares there is no conflict of interest.

\section{References}

1. Pappo A, Barr F, Wolden S, et al. Pediatric Bone and Soft Tissue Sarcomas, first edition. Berlin. Springer. 2006;103-132.

2. Kamat MR, Kulkarni JN, Tongaonkar HB, et al. Rhabdomyosarcoma of the bladder and prostate in children. J Surg Oncol. 1991;48(3): 180-182.

3. Cervantes I, Camacho E, Orozco J, Gutiérrez R, Aguirre O. Rhabdomyosarcoma of the bladder floor: a case report and literature review. Rev Mex de Cir Ped. 2010; 17:79-84.

4. Neville HL, Andrassy RJ, Lobe TE, et al. Preoperative staging, prognostic factors, and outcome for extremity rhabdomyosarcoma: A preliminary report from the Intergroup Rhabdomyosarcoma Study IV (1991 - 1997). Journal of Pediatric Surgery 2000; 35:317.

5. Osaki M, Takahashi C, Miyagawa T. Prostatic stromal sarcoma: case report and review of the literature. Pathol. Int. 2003; 53:407-411.

6. Lara C, Borrero J, Porras V, Giraldez J. Sarcoma del estroma prostático en un paciente de 20 años de edad. Arch. Esp. Urol., 2005; 58:947-949.

7. A.G. Coran, A. Caldamone, N.A. Adzick, et al. Chapter 35 - Diagnosis and treatment of rhabdomyosarcoma (7th ed.), En: Textbook Pediatric Surgery, vol. 1, Elsevier, Philadelphia, PA EU (2012), p. 522. 